\title{
SPT5, an Essential Gene Important for Normal Transcription in Saccharomyces cerevisiae, Encodes an Acidic Nuclear Protein with a Carboxy-Terminal Repeat
}

\author{
MICHELE S. SWANSON, ELIZABETH A. MALONE, AND FRED WINSTON* \\ Department of Genetics, Harvard Medical School, Boston, Massachusetts 02115
}

Received 28 January 1991/Accepted 13 March 1991

\begin{abstract}
Mutations in the SPT5 gene of Saccharomyces cerevisiae were isolated previously as suppressors of $\delta$ insertion mutations at HIS4 and LYS2. In this study we have shown that spt5 mutations suppress the his4-9128 and lys2-128 alleles by altering transcription. We cloned the SPT5 gene and found that either an increase or a decrease in the copy number of the wild-type $S P T 5$ gene caused an $\mathrm{Spt}^{-}$phenotype. Construction and analysis of an spt5 null mutation demonstrated that SPT5 is essential for growth, suggesting that SPT5 may be required for normal transcription of a large number of genes. The SPT5 DNA sequence was determined; it predicted a 116-kDa protein with an extremely acidic amino terminus and a novel six-amino-acid repeat at the carboxy terminus (consensus = S-T/A-W-G-G-A/Q). By indirect immunofluorescence microscopy we showed that a bifunctional SPT5- $\beta$-galactosidase protein was located in the yeast nucleus. This molecular analysis of the SPT5 gene revealed a number of interesting similarities to the previously characterized SPT6 gene of $S$. cerevisiae. These results suggest that SPT5 and SPT6 act in a related fashion to influence essential transcriptional processes in $S$. cerevisiae.
\end{abstract}

A large number of mutations that alter transcription in the yeast Saccharomyces cerevisiae were isolated by selection for suppressors of Ty or solo $\delta$ insertion mutations at HIS4 and $\operatorname{LYS} 2(19,64,65)$. These mutations have identified 16 unlinked genes, named $S P T$ genes (for suppressor of Ty). Molecular analysis has revealed that three of the SPT genes encode proteins that are believed to play central roles in gene expression: SPT15 encodes the TATA-binding protein TFIID (16), and SPTII and SPTI2 are the same as the genes $H T A l$ and $H T B l$, which encode the histone proteins $\mathrm{H} 2 \mathrm{~A}$ and $\mathrm{H} 2 \mathrm{~B}$, respectively (12). Genetic analysis of the remaining spt mutants allowed classification of most of the SPT genes into three groups, based on distinct mutant phenotypes: the first group includes $S P T 11$ and $S P T 12$, the second includes $S P T 15$, and the third includes $S P T 13 / G A L 11$ (19, 20).

The SPT5 gene, characterized in this study, and the SPT6 gene, analyzed previously $(13,45,61)$, belong to the phenotypic class represented by the histone genes HTAl/SPTII and $H T B 1 / S P T 12(12,19)$. Mutations in each of these genes suppress the same set of Ty and $\delta$ insertion mutations at the HIS4 and LYS2 genes $(19,64)$ as well as some cis- and trans-acting mutations that severely reduce the expression of the SUC2 gene and Ty elements $(11,26,45,46,62)$. Previous studies also demonstrated that altered dosage of the SPT6 gene or the HTA1-HTB1 locus causes similar mutant phenotypes $(12,13,45)$. Molecular analysis demonstrated that SPT6 encodes an essential nuclear protein of 170 $\mathrm{kDa}$ with an extremely acidic amino terminus $(13,45,61)$. These studies suggested that SPT6 plays an essential role in transcription, perhaps by affecting chromatin structure.

On the basis of the observation that spt5 mutants are phenotypically similar to spt6 and histone mutants, we decided to analyze the SPT5 gene and its product. In this study, we have demonstrated that mutations in the SPT5

\footnotetext{
* Corresponding author
}

gene suppress $\delta$ insertion mutations by altering transcription. We cloned the SPT5 gene and used the cloned gene for additional molecular and genetic studies of SPT5. The nucleotide sequence of the SPT5 gene predicts a 1,063-aminoacid protein with a highly acidic amino terminus and 15 copies of a six-amino-acid repeat at the carboxy terminus. Analysis of the SPT5 repeat domain indicated that this region is required for SPT5 function. Like SPT6, SPT5 is essential for growth, proper SPT5 gene dosage is critical for function, and the SPT5 protein appears to be located in the yeast nucleus. This molecular analysis supports the idea that SPT5 and SPT6 are functionally related and are required for normal transcription in $S$. cerevisiae.

\section{MATERIALS AND METHODS}

Strains and genetic methods. All $S$. cerevisiae strains used in these studies (Table 1) were constructed in this laboratory and are derivatives of strain S288C (MAT $\alpha$ gal2) except for strains YPH149 (24), SF402-4D (Yeast Genetic Stock Center, Berkeley, Calif.), and K396-11A and K396-22B (36). Parentheses indicate autonomous plasmids, brackets indicate integrated plasmids, and double brackets indicate autonomous linear chromosomal fragments. Standard methods for mating, sporulation, and tetrad analysis were used (43, 56). The lys2-128ס allele consists of a solo $\delta$ element inserted 153 bp downstream of the LYS 2 translation initiation codon $(13,59)$. The his4-912 $\delta$ allele is an insertion of a solo $\delta$ element at bp -97 relative to the HIS4 transcription initiation site $(8,18)$. Strains MS194 and MS195 contain SPT5-lacZ hybrid genes integrated at the spt5 $\Delta 202:: L E U 2$ allele. These strains were constructed by transforming the diploid strain BM80 with pMS50 DNA (MS194) or pBM68 DNA (MS195) that had been linearized by restriction digestion with PstI. The site of integration was determined by sporulating transformants, dissecting tetrads, and scoring the Ura and Leu phenotypes of the spore clones.

Media. Rich medium (YPD), minimal medium (SD), sup- 
TABLE 1. Yeast strains

\begin{tabular}{|c|c|}
\hline Strain & Genotype \\
\hline \multicolumn{2}{|r|}{ MATa ura3-52 leu2 $\Delta 1$} \\
\hline \multicolumn{2}{|r|}{ MATa spt5-194 leu2 $\Delta l$} \\
\hline \multicolumn{2}{|r|}{ MATa spt5-8 ura3-52 leu $2 \Delta l$} \\
\hline \multicolumn{2}{|c|}{ 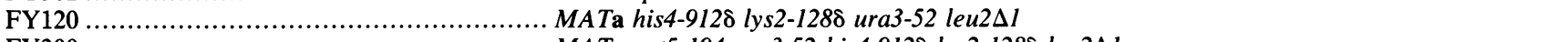 } \\
\hline \multicolumn{2}{|c|}{ 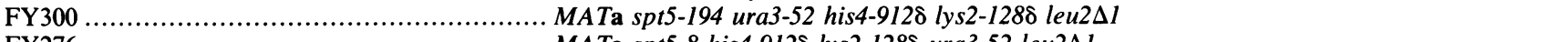 } \\
\hline \multicolumn{2}{|c|}{ 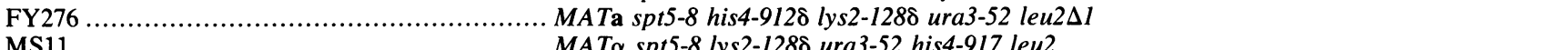 } \\
\hline \multicolumn{2}{|c|}{ 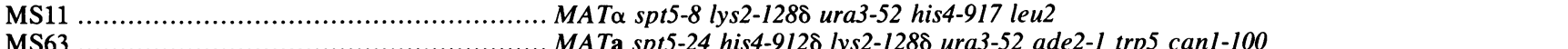 } \\
\hline \multicolumn{2}{|c|}{ 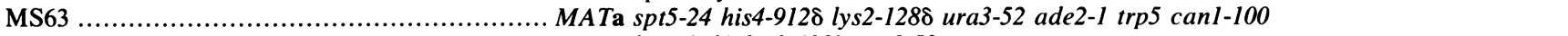 } \\
\hline \multicolumn{2}{|c|}{ 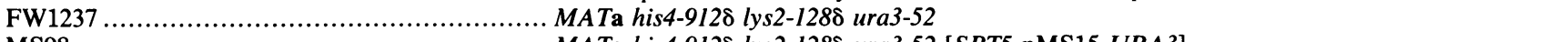 } \\
\hline \multirow{2}{*}{\multicolumn{2}{|c|}{$\begin{array}{l}\text { a } \\
\ldots\end{array}$}} \\
\hline & MAT $\alpha$ spt5-24 his4-9128 lys2-1288 ura3-52 ade2-1 canl-100 \\
\hline \multicolumn{2}{|c|}{ 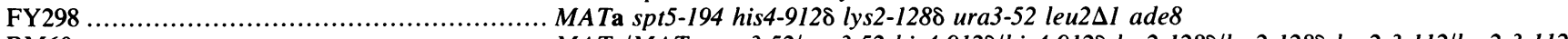 } \\
\hline \multicolumn{2}{|c|}{ 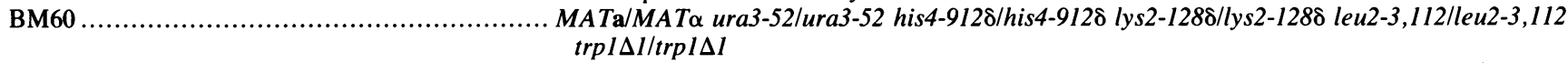 } \\
\hline \multicolumn{2}{|c|}{ 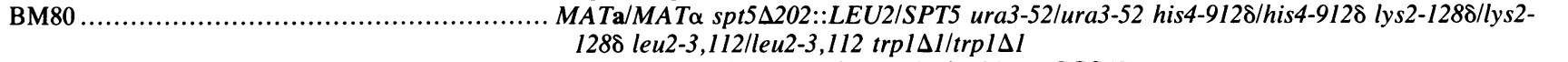 } \\
\hline \multicolumn{2}{|c|}{ 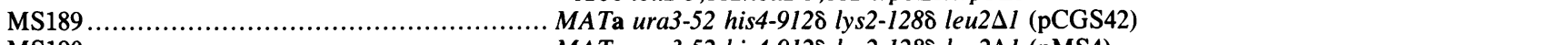 } \\
\hline \multicolumn{2}{|c|}{ 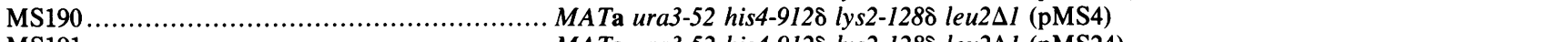 } \\
\hline \multicolumn{2}{|c|}{ 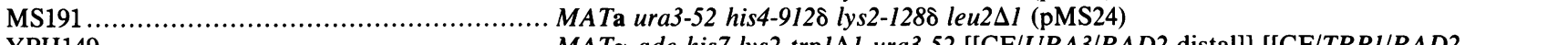 } \\
\hline \multicolumn{2}{|c|}{ 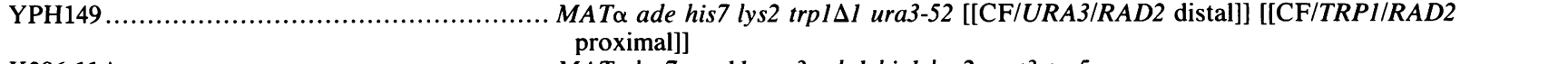 } \\
\hline \multirow{2}{*}{\multicolumn{2}{|c|}{ 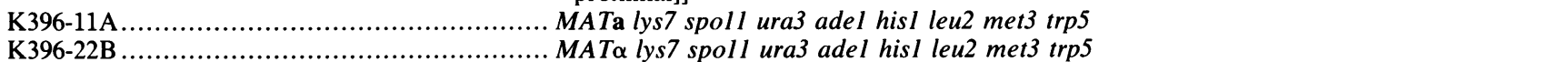 }} \\
\hline & \\
\hline \multicolumn{2}{|c|}{ 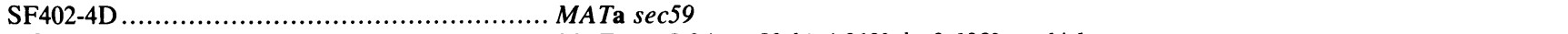 } \\
\hline \multicolumn{2}{|c|}{ 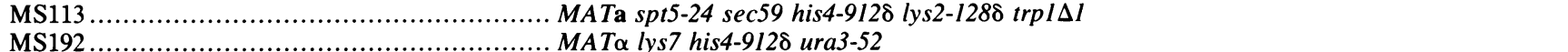 } \\
\hline \multicolumn{2}{|c|}{ 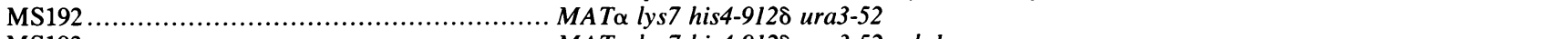 } \\
\hline \multirow{2}{*}{\multicolumn{2}{|c|}{ 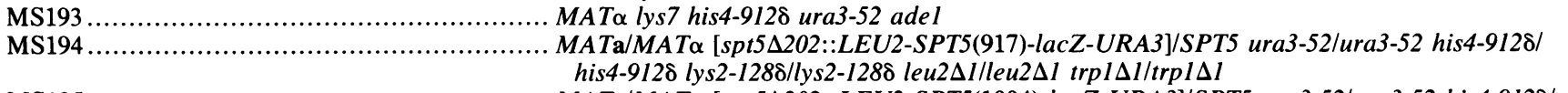 }} \\
\hline & \\
\hline \multicolumn{2}{|c|}{ 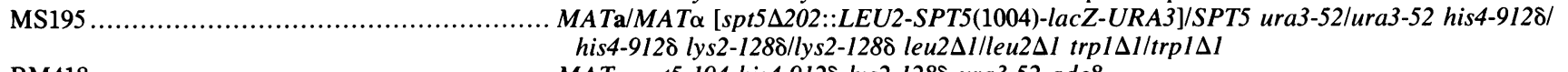 } \\
\hline \multicolumn{2}{|c|}{ 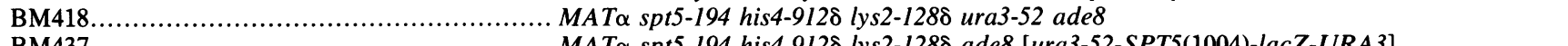 } \\
\hline \multicolumn{2}{|r|}{ 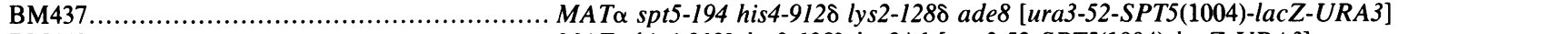 } \\
\hline \multicolumn{2}{|r|}{ 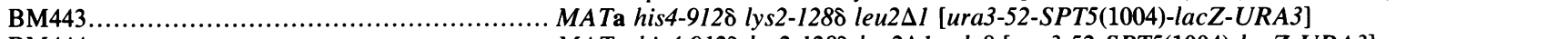 } \\
\hline \multicolumn{2}{|r|}{ 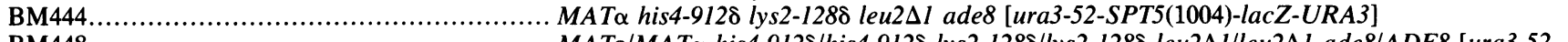 } \\
\hline \multicolumn{2}{|c|}{ 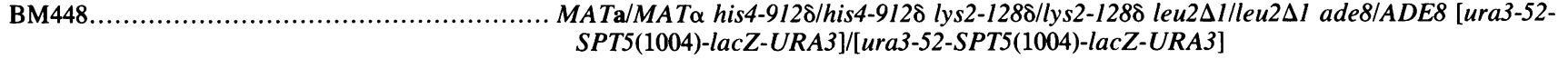 } \\
\hline \multicolumn{2}{|c|}{ 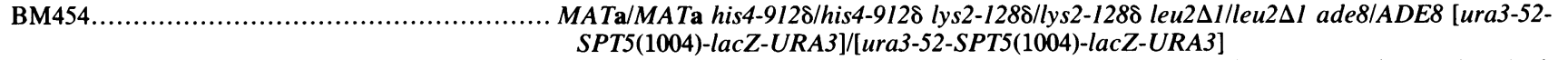 } \\
\hline BM455. & 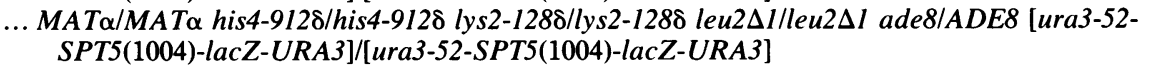 \\
\hline BM467.. & $\ldots \mathrm{BM} 454 \times \mathrm{BM} 455$ \\
\hline BM330.. & 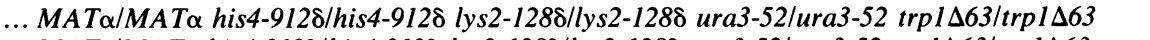 \\
\hline BM331.. & 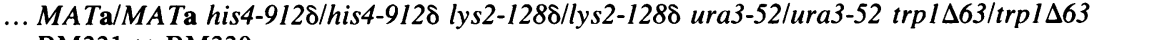 \\
\hline BM339. &. BM331 × BM330 \\
\hline
\end{tabular}

plemented SD (SD to which amino acids were added from liquid stock solutions), synthetic complete medium lacking a single amino acid, and sporulation medium were prepared as described previously by Sherman et al. (56). GNA presporulation medium contained $10 \mathrm{~g}$ of yeast extract, $30 \mathrm{~g}$ of nutrient broth, $50 \mathrm{~g}$ of dextrose, and $20 \mathrm{~g}$ of agar per liter.

Transformations. Yeast cells were transformed by the lithium acetate method (32). Escherichia coli HB101 (3) and TB1 (Bethesda Research Laboratories, Gaithersburg, Md.) were transformed as described previously (41).

Enzymes. Restriction enzymes were purchased from Boehringer Mannheim Biochemicals (Indianapolis, Ind.) and New England BioLabs (Beverly, Mass.). T4 DNA ligase was purchased from New England BioLabs. All enzymes were used according to the instructions of the supplier.

DNA preparation and analysis. Yeast genomic and plasmid DNAs were prepared as described previously (28). E. coli plasmid DNA was prepared by the method of Holmes and Quigley (29) or Birnboim and Doly (2). DNA restriction fragments were separated by electrophoresis through
Seakem agarose (FMC Bioproducts, Rockland, Maine) and purified by electroelution, using a device designed by Larry Peck (49). Southern blot hybridization analysis was performed as described previously (51). Radiolabeled DNA probes were prepared by nick translation $(50)$ or random priming $(21,22)$, using $\left[\alpha{ }^{32} \mathrm{P}\right] \mathrm{dATP}$ (Amersham) and reagent kits from Boehringer Mannheim.

RNA preparation and analysis. Yeast RNA was prepared as described previously (7) from cells grown in supplemented SD medium at $25^{\circ} \mathrm{C}$ to a density of $1 \times 10^{7}$ to $2 \times 10^{7}$ cells per ml. RNA was separated in formaldehyde-agarose gels. After denaturation in $0.05 \mathrm{M} \mathrm{NaOH}$ and renaturation in $0.1 \mathrm{M}$ Tris ( $\mathrm{pH} 7.5$ ), the RNA was transferred to GeneScreen (New England Nuclear, Boston, Mass.) by capillary blotting in $1 \times \operatorname{SSC}(0.15 \mathrm{M} \mathrm{NaCl}, 0.015 \mathrm{M}$ sodium citrate $)$. RNA was cross-linked to the membrane by UV irradiation (10). Probes were hybridized by the dextran sulfate method as described in the GeneScreen instruction manual. Additional probes were hybridized after the membrane was stripped in $1 \times$ SSC-50\% formamide at $80^{\circ} \mathrm{C}$ for $2 \mathrm{~h}$. The amount of RNA in 
each lane was normalized by hybridization to TUB2 DNA (plasmid pYST138; 60).

Plasmids. Vectors used for SPT5 subcloning were YCp50 (34) for pMS37 and pRS316 (57) for pMS18 and pMS23. Subclones were tested for SPT5 function after transformation into the spt5 mutant strain MS63(pMS18) or FY298 (pMS23, pMS37). For integration of the cloned yeast DNA, we constructed plasmid pMS15 by cloning the $4.0-\mathrm{kb}$ HindIII-KpnI fragment of pMS4 into the HindIII-KpnI sites of the integrating plasmid pRS306 (57). To study the effects of multiple copies of the SPT5 gene, plasmid pMS24 was constructed by cloning the 4.8-kb HindIII-EagI fragment of pMS4 into the HindIII-EagI sites of the vector pCGS42 (Collaborative Research), which contains part of $2 \mu \mathrm{m}$ circle. Plasmids used as probes were as follows: for HIS4, pFW45, a $B g I I I-S a l I$ restriction fragment internal to $H I S 4$ cloned in pBR322 (66); for $L Y S 2$, pFW47, a $B g l \mathrm{II}-X$ hoI restriction fragment internal to $L Y S 2$ cloned in pBR322 (13), and pFW112, an EcoRI-BglII restriction fragment from the $5^{\prime}$ region of $L Y S 2$ cloned in pBR322 (13); for TUB2, pYST138, a 0.24-kb BglII-KpnI restriction fragment internal to $T U B 2$ cloned in a pGEM vector (60); and for SPT5, pMS22, a 4.0-kb HindIII-KpnI fragment from pMS4 cloned in pBR322.

We constructed fusions of SPT5 to the $E$. coli lacZ gene by using integrating plasmids containing a polylinker followed by the lacZ gene and the URA3 gene as a selectable marker (42). Plasmid pBM68 was constructed by cloning the $4.0-\mathrm{kb}$ HindIII-KpnI restriction fragment of pMS4 into the HindIII and KpnI sites of YIp356R; the SPT5-lacZ fusion gene contained on pBM68, designated SPT5(1004)-lacZ, encodes the first 1,004 amino acids of SPT5. Plasmid pMS50 was constructed by cloning the 3.7-kb HindIII-PvuII restriction fragment of pMS4 into the HindIII-SmaI sites of YIp357R; the SPT5-lacZ fusion gene contained on pMS50, designated SPT5(917)-lacZ, encodes the first 917 amino acids of SPT5. Plasmids pBM68 and pMS50 each have a unique StuI restriction site in the $U R A 3$ gene and a unique Pst I site in the SPT5 gene that are useful for directing integration of the plasmids to the URA3 and SPT5 genes, respectively, in transformation experiments.

We observed that $E$. coli strains carrying SPT5 DNA on high-copy-number plasmids formed unusually small colonies.

Construction of an spt5 null allele. To construct the spt5 null allele, spt5 $\Delta 202:: L E U 2$, we replaced the 0.8 -kb SalISalI restriction fragment of pMS23 with a 2.2-kb Sall-XhoI restriction fragment containing the $L E U 2$ gene (1) to generate plasmid pBM19. Next, the 3.1-kb PvuII-PstI restriction fragment from $\mathrm{pBM} 19$, which contains the $L E U 2$ gene flanked by SPT5 sequences, was used to transform the diploid BM60 to leucine prototrophy. Strain BM80 is a stable $\mathrm{Leu}^{+}$transformant resulting from recombination between the fragment and the genome such that one copy of the SPT5 gene was replaced by the null allele (53). The structure of the SPT5 loci of the diploid BM80 was verified by Southern hybridization analysis (data not shown). The phenotype of the spt5 null allele in haploids was analyzed following sporulation of BM80 and dissection of tetrads.

Mapping SPT5. The method of Carle and Olson (6) was used to prepare chromosome-size DNA from strain YPH149. Chromosome VII of YPH149 has been fragmented at $R A D 2$ to allow all of the yeast chromosomes to be resolved as discrete bands by alternating field gel electrophoresis (24). DNA was separated by clamped homogeneous electric field (CHEF) gel electrophoresis (9) through $0.9 \%$ agarose in $0.5 \times \mathrm{TBE}$ buffer $(45 \mathrm{mM}$ Tris base, $45 \mathrm{mM}$ boric acid, $1.25 \mathrm{mM}$ EDTA). After electrophoresis, the gel was soaked sequentially for $20 \mathrm{~min}$ each in $0.25 \mathrm{M} \mathrm{HCl}, 0.5 \mathrm{M}$ $\mathrm{NaOH}-1.0 \mathrm{M} \mathrm{NaCl}$, and 1.5 M NaCl-1.0 M Tris (pH 7.4). The DNA was transferred to nitrocellulose by capillary blotting in $4 \times$ SSC. Radiolabeled pMS4 DNA hybridized to several chromosomes as a result of its composition: chromosome IV (CEN4), chromosome V (URA3), both fragments of chromosome VII (pBR322, URA3), and chromosome XIII (SPT5). Linkage of SPT5 to its centromere and to markers on chromosome XIII was determined by tetrad analysis. spt5-24 was scored by its ability to suppress the $\mathrm{His}^{-}$phenotype conferred by the $\delta$ insertion mutation his 4 9128. The sec59 allele of MS113 was derived from strain SF402-4D.

DNA sequence analysis. Restriction fragments to be sequenced were cloned into the vector M13mp18 or M13mp19 (48). The nucleotide sequence was determined by the method of Sanger et al. (54), using $\left[\alpha^{35}\right.$ S]dATP (Amersham) and the Sequenase version 2.0 kit (U.S. Biochemical Corp., Cleveland, Ohio). In 12 cases, where there were no convenient restriction sites, 20-base oligomers were synthesized (Mark Fleming, Biopolymers Laboratory, Department of Genetics, Harvard Medical School) and used as primers. The complete DNA sequence was determined on both strands.

Indirect immunofluorescence. For indirect immunofluorescence experiments, we used tetraploid cells because they are larger than haploid cells. A tetraploid strain containing an SPT5-lacZ fusion was constructed in several steps. First, we constructed haploid strains containing the SPT5(1004)-lacZ fusion by transforming strain BM418 to uracil prototrophy with pBM68 DNA that had been linearized by digestion with StuI. Next, a stable integrant from this transformation, BM437, was crossed with strain FY120 to yield SPT5 strains carrying the SPT5(1004)-lacZ fusion. Two of these strains (BM443 and BM444) were then mated by each other to form the diploid BM448. We isolated diploids homozygous at $M A T$ by UV irradiating BM448 $\left(300 \mathrm{ergs} / \mathrm{mm}^{2}\right)$ and screening for diploids that could mate as either a or $\alpha$ cells. Mating of the $M A T \mathrm{a} / M A T$ a diploid BM454 by the $M A T \alpha / M A T \alpha$ diploid BM455 yielded the tetraploid strain BM467, which carries four copies of the SPT5(1004)-lacZ fusion. Strain BM339, similar to BM467 except that it does not contain an SPT5lac $Z$ fusion, was constructed by the same method.

Cells were prepared for immunofluorescence by the method of Kilmartin and Adams (35) with the modifications described previously (61). The SPT5- $\beta$-galactosidase fusion protein was identified by incubating the prepared cells with a monoclonal rabbit anti- $\beta$-galactosidase antibody (Cappel, Malvern, $\mathrm{Pa}$.) diluted 1:10,000 and a fluorescein-conjugated goat anti-rabbit antibody (Sigma, St. Louis, Mo.) diluted $1: 250$. DNA was stained with the fluorescent dye $4^{\prime}, 6^{\prime}$ diamidino-2-phenylindole dihydrochloride (DAPI). Fluorescent staining was visualized by using a Zeiss Photomicroscope III equipped for epi-illumination fluorescence with a Zeiss Neofluar $63 \times$ lens, numerical aperture 1.25 , and photographed with Kodak TMAX-400 film. The exposure time for micrographs of fluorescein fluorescence in the experimental and control strains was $30 \mathrm{~s}$.

Nucleotide sequence accession number. The GenBank accession number for the SPT5 sequence is M62882.

\section{RESULTS}

spt5 mutations alter transcription. Recessive mutations in SPT5 had been identified as suppressors of the insertion 


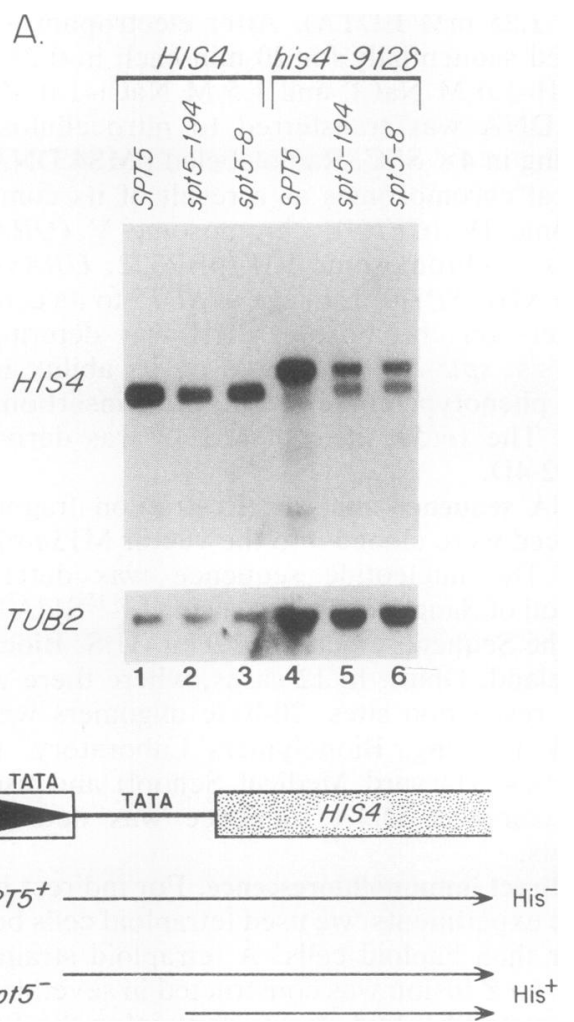

FIG. 1. Effects of spt5 mutations on transcription of his4-9128. (A) Total yeast RNA was subjected to Northern analysis. The same membrane was hybridized with the HIS4 probe pFW45 and then rehybridized with TUB2 probe pYST138. Approximately $2.5 \mu \mathrm{g}$ of RNA was loaded in lanes 1 to 3 , and approximately $10 \mu \mathrm{g}$ was loaded in lanes 4 to 6 . The strains used were (left to right) FY98, FY360, FY382, FY120, FY300, and FY276. (B) The top line depicts the structure of his4-9128. The gray box represents the HIS4 open reading frame. The thin lines represent flanking DNA. The box with the solid triangle represents a solo $\delta$ element. Labels above indicate the relative positions of known TATA boxes (TATA) and upstream activating sequences (UAS). The lower lines depict the probable origins of transcripts in $S P T 5^{+}$and spt5 strains.

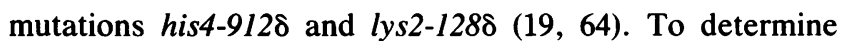
whether the phenotypic changes in spt5 mutants result from alterations in transcription, we performed Northern (RNA) hybridization analysis. Our results (Fig. 1 and 2) demonstrate that spt 5 mutations cause altered transcription at both his4-9128 and lys2-1288.

In an $S P T^{+}$background, transcription of his4-9128 initiates at the $\delta$ initiation site and results in an mRNA that is longer than the wild-type HIS4 mRNA (27, 58; Fig. 1). The 5 ' portion of this transcript contains in-frame translation initiation and termination codons which presumably prevent normal translation of the HIS4 coding region (58). In both spt5-194 and spt5-8 mutants, a shorter transcript that comigrated with the wild-type HIS4 mRNA was produced in addition to the $\delta$-initiated transcript (Fig. 1A, lanes 5 and 6). The levels of the two transcripts were roughly equal. The size of the new transcript indicates that spt5 mutations allow transcription initiation at the normal HIS4 initiation site (Fig. 1B). This same alteration in his4-912 $\delta$ transcription is seen in spt6 and htal-htbl (histone) mutants $(12,13)$.

Mutations in SPT5 also affected transcription of lys2-1288. In $S P T^{+}$strains, transcription of lys $2-128 \delta$ resulted in a short

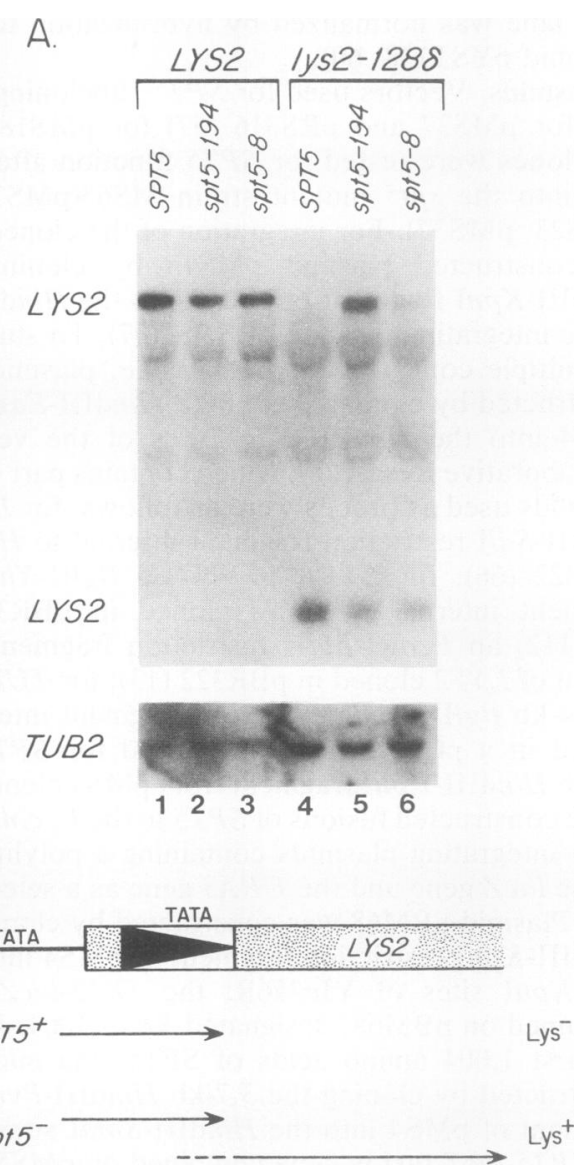

FIG. 2. Effects of spt5 mutations on transcription of lys2-1288. (A) Total yeast RNA was subjected to Northern analysis. The same membrane was hybridized with a mixture of the LYS2 probes pFW47 and pFW112 and then rehybridized with the TUB2 probe pYST138. Since the smaller LYS2 RNA is much more abundant, the pFW47 probe contained approximately 10 -fold more counts per minute than the pFW112 probe. Approximately $2.5 \mu \mathrm{g}$ of RNA was loaded in lanes 1 to 3 , and approximately $10 \mu \mathrm{g}$ was loaded in lanes 4 to 6 . The strains used were the same as those given for Fig. 1A. (B) The top line depicts the structure of lys2-128ס. The gray box represents the $L Y S 2$ open reading frame. The thin lines represent flanking DNA. The box with the solid triangle represents a solo $\delta$ element. Labels above indicate the relative positions of known TATA boxes (TATA) and upstream activating sequences (UAS). The lower lines depict the probable origins of transcripts in $S P T 5^{+}$ and $s p t 5$ strains.

transcript of approximately 580 bases (Fig. 2A, lane 4), probably due to initiation at the LYS2 initiation site and termination at the $\delta$ transcription termination site (13; Fig. 2B). In spt 5 mutant strains, a second transcript was also produced (Fig. 2A, lanes 5 and 6). For spt5-194 mutants, this second transcript was easily seen; for spt5-8 mutants, the new transcript was found at a low level and could be seen more clearly with longer exposures. (The two strains were equally $\mathrm{Lys}^{+}$.) This mRNA is slightly shorter than the wild-type LYS2 transcript and is likely to result from transcription initiation near the $\delta$ initiation site and elongation through the LYS2 gene (Fig. 2B). Mutations in SPT6 and HTAl-HTBI cause similar changes in lys2-1288 transcription $(12,13)$.

Transcription of other sequences was also examined. The 

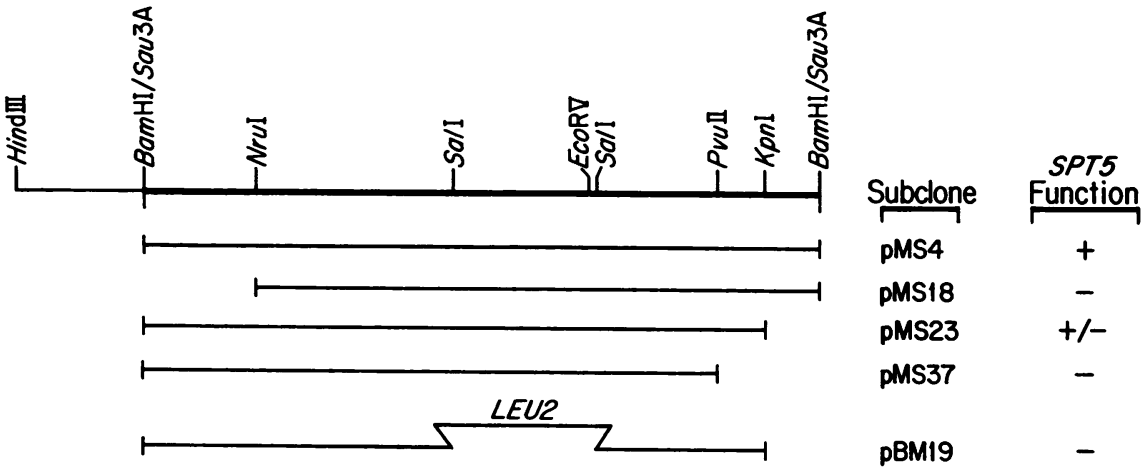

$\overline{1 \mathrm{~kb}}$

FIG. 3. Restriction map of the SPT5 locus. The top line represents the SPT5 locus and its restriction sites. The thinner portion of the line represents vector sequences. The lines below represent DNA fragments that were subcloned to test for SPT5 function. Plasmid pBM19 was used to construct an spt5 null mutant.

level of the wild-type HIS4 and LYS2 transcripts was slightly reduced by spt 5 mutations (Fig. 1A, lanes 1 to 3; Fig. 2A, lanes 1 to 3 ). There was no reduction in the level of full-length Ty transcripts in spt5 mutants (data not shown). Similarily, spt6 and htal-htbl (histone) mutations do not affect the level of full-length Ty transcripts $(4,13)$. In contrast, spt mutants in a different phenotypic class (spt3, $s p t 7, s p t 8$, and $s p t 15$ ) abolish or greatly reduce the level of full-length Ty transcripts $(17,65,66)$.

Isolation of the SPT5 gene. An SPT5 gene clone was isolated from a library of yeast DNA (52) by screening for plasmids that complemented an spt 5 mutant phenotype. The recipient strain, MS11 (spt5-8 lys2-1288 ura3-52), is Lys ${ }^{+}$ due to suppression of lys $2-128 \delta$ by $s p t 5-8$. Since $s p t 5-8$ is recessive, transformants of MS11 that carry the wild-type SPT5 gene on a plasmid should be Lys ${ }^{-}$. Two Lys ${ }^{-}$candidates were identified in a screen of approximately 15,000 $\mathrm{Ura}^{+}$transformants; both contained the same DNA insert, and one of these plasmids was designated pMS4. This plasmid conferred an $\mathrm{Spt}^{+}$phenotype when retransformed into strain MS11 or when transformed into strain MS63, which contains a different spt5 allele.

We confirmed that pMS4 contained the SPT5 gene by demonstrating that the cloned DNA directed integration of a plasmid to the SPT5 locus. Plasmid pMS15, an integrating plasmid that contains a restriction fragment from pMS4, was linearized at a unique $N r u I$ site within the cloned DNA and used to transform FW1237 (SPT5 $^{+}$ura3-52 lys2-1288) to uracil prototrophy. A $\mathrm{Ura}^{+}$transformant (MS98) was crossed to strain MS17 (spt5-24 ura3-52 lys2-1288), and tetrads were dissected. In 17 four-spored and nine threespored tetrads, the $\mathrm{Spt}^{+}$and $\mathrm{Ura}^{+}$phenotypes cosegregated in every tetrad, demonstrating that pMS15 DNA was tightly linked to the SPT5 locus.

To characterize the SPT5 gene in greater detail, several subclones were constructed and tested for SPT5 function (Fig. 3). Although the HindIII-KpnI fragment (pMS23) partially complemented the spt5-194 allele, none of the subclones fully complemented the mutant phenotype, suggesting that the SPT5 gene occupies most of the cloned $3.9-\mathrm{kb}$ DNA fragment.

Construction and analysis of an spt5 null mutant. We constructed an spt5 null allele marked by the $L E U 2$ gene, spt5 $202:: L E U 2$, by deleting the SalI-SalI restriction fragment internal to SPT5 (Fig. 3) and replacing it with the $L E U 2$ gene (see Materials and Methods). Integration of this allele into the diploid strain BM60 resulted in a strain heterozygous for the null allele. After sporulation and tetrad dissection of this strain (BM80), viability segregated 2:2 (9 of 10 tetrads) or $1: 3$ ( 1 of 10 tetrads). In all cases, the viable spores were $\mathrm{Leu}^{-}$, indicating that they carried the wild-type SPT5 gene. Therefore, the SPT5 gene is essential for growth.

Altered SPT5 gene dosage causes mutant phenotypes. Altered dosage of the SPT6 or the HTAI-HTBI locus confers an $\mathrm{Spt}^{-}$mutant phenotype $(12,13,45)$. To test whether altered SPT5 gene dosage causes similar phenotypes, we constructed a set of isogenic strains that had either a reduced or increased copy number of the SPT5 gene. These strains were then tested for suppression of the insertion mutations his4-912 8 and lys2-1288. A diploid strain (BM80) that contained only one copy of the SPT5 gene $\left(S P T 5^{+}\right.$ spt5 $202:: L E U 2)$ had a strong $\mathrm{Spt}^{-}$phenotype $\left(\mathrm{His}^{+} \mathrm{Lys}^{+}\right.$) (Fig. 4). A haploid SPT5 ${ }^{+}$strain (MS191) transformed with a multicopy SPT5 plasmid (pMS24) had a weak $\mathrm{Spt}^{-}$phenotype $\left(\mathrm{His}^{+1-} \mathrm{Lys}^{+1-}\right.$ ) (Fig. 4). Therefore, an increase or a decrease in the SPT5 gene copy number causes an $\mathrm{Spt}^{-}$ phenotype.

Genetic mapping of SPT5. To determine whether SPT5 was a previously identified gene, it was mapped by a combination of physical and genetic methods. To determine the chromosome on which the SPT5 gene resides, DNA was prepared from strain YPH149, and chromosomes were separated by CHEF gel electrophoresis (9) as described in Materials and

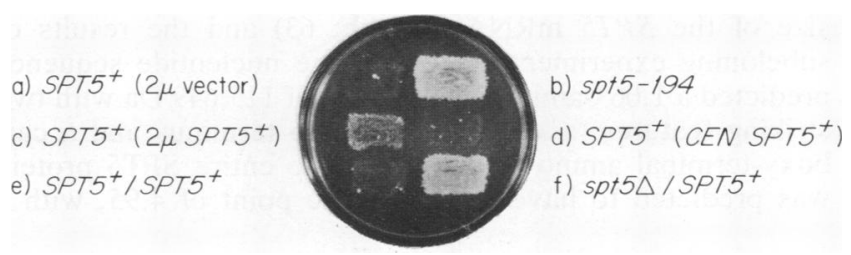

FIG. 4. Suppression of the insertion mutation lys2-1288 by altered SPT5 gene dosage. Patches of the strains of the genotypes indicated were grown on a YPD plate and then replica plated to the plate shown, which contains SC-lys medium. All strains grew on a synthetic complete plate (not shown). (a) MS189(pCGS42); (b) FY300; (c) MS191(pMS24); (d) MS190(pMS4); (e) BM60; (f) BM80. 


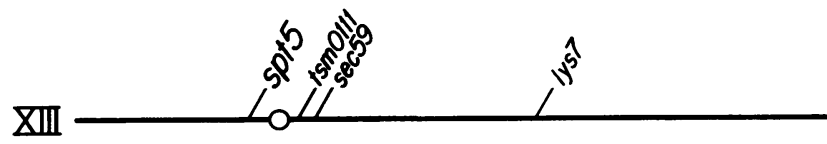

FIG. 5. Genetic map position of SPT5. The SPT5-CEN13 distance was strain dependent (see text).

Methods. Southern hybridization analysis demonstrated that SPT5 was located on chromosome XIII (63).

Tetrad analysis showed that SPT5 was located on the left arm of chromosome XIII, tightly centromere linked (Table 2; Fig. 5). The order SPT5-CEN13-SEC59 was determined by examining tetrads in which SPT5 and CEN13 had recombined; in every case (seven tetrads), SEC59 and CEN13 did not recombine. This order was also consistent with the segregation of SPT5 in tetrads in which CEN13 and SEC59 had recombined. Similarly, the order SPT5-SEC59-LYS7 was established by scoring LYS7 segregation in tetrads in which SPT5 and SEC59 had recombined. In those 13 tetrads, SEC59 and LYS7 had recombined once, whereas SPT5 and LYS7 had recombined 12 times. These results, in conjunction with previous work that showed that LYS7 maps physically to the right arm of chromosome XIII (23), indicated that SPT5 resides on the left arm of chromosome XIII. Additional meiotic linkage analysis demonstrated that SPT5 was not an allele of the centromere-linked TSM0111 locus, since in one cross (82 tetrads), SPT5 mapped 4.9 centimorgans (cM) from TSM0111 (63). Therefore, based on its unique map position, SPT5 is a previously uncharacterized gene in $S$. cerevisiae.

The map distance between SPT5 and CEN13 was strain dependent; two representative crosses are shown in Table 2. In a cross of strain MS113 by strain MS192, there were no CEN13-SPT5 recombinants in 80 tetrads $(<0.6 \mathrm{cM}$; Table 2$)$. In contrast, when strain MS113 was crossed by strain MS193, there were seven CEN13-SPT5 recombinants in 51 tetrads (7 cM; Table 2). Analysis of SPT5 segregation with respect to different centromere-linked markers, TRPI (chromosome IV) and URA3 (chromosome V), showed that the difference between strains MS192 and MS193 lies in the CEN13-SPT5 interval (Table 2). Similar results were obtained in other SPT5 crosses: the CEN13-SPT5 map distance was calculated as either $<1 \mathrm{cM}$ or approximately $5 \mathrm{cM}(63)$. The observation that the genetic map position of SPT5 was strain dependent indicates that there are polymorphisms (possibly insertions or inversions) in the CEN13 region of some strains.

SPT5 encodes an acidic protein with a carboxy-terminal repeat. The nucleotide sequence of the SPT5 gene was determined by the method of Sanger et al. (54). The open reading frame of 3,189 bp (Fig. 6) was consistent with the size of the SPT5 mRNA $(3.4 \mathrm{~kb} ; 63)$ and the results of subcloning experiments (Fig. 3). The nucleotide sequence predicted a 1,063-amino-acid protein of $115,649 \mathrm{Da}$ with two striking features: a very acidic amino terminus and a carboxy-terminal amino acid repeat. The entire SPT5 protein was predicted to have an isoelectric point of 4.95 , with a
TABLE 2. Mapping SPT5 by tetrad analysis ${ }^{a}$

\begin{tabular}{|c|c|c|c|c|c|c|}
\hline \multirow{2}{*}{$\operatorname{Cross}^{b}$} & \multirow{2}{*}{$\begin{array}{c}\text { Segregating } \\
\text { markers }\end{array}$} & \multirow{2}{*}{ PD } & \multirow{2}{*}{ NPD } & \multirow{2}{*}{ TT } & \multicolumn{2}{|c|}{ Linkage (cM) } \\
\hline & & & & & Gene-gene & Gene- $C E N$ \\
\hline \multirow[t]{8}{*}{1} & spt5, sec59 & 76 & 0 & 4 & 3 & \\
\hline & spt 5, lys 7 & 41 & 0 & 39 & 24 & \\
\hline & $\sec 59$, lys 7 & 43 & 0 & 37 & 23 & \\
\hline & spt5, trpl & 42 & 38 & 0 & & $<0.6$ \\
\hline & sec59, trpl & 39 & 36 & 5 & & 3 \\
\hline & lys $7, \operatorname{trpl}$ & 20 & 20 & 40 & & 25 \\
\hline & trpl, ura3 & 36 & 32 & 12 & & 8 \\
\hline & spt 5, ura 3 & 35 & 34 & 11 & & 7 \\
\hline \multirow[t]{8}{*}{2} & spt5, sec59 & 42 & 0 & 9 & 9 & \\
\hline & spt 5 , lys 7 & 19 & 0 & 32 & 31 & \\
\hline & sec 59, lys 7 & 28 & 0 & 23 & 23 & \\
\hline & spt5, trpl & 23 & 21 & 7 & & 7 \\
\hline & sec 59, trpl & 23 & 26 & 2 & & 2 \\
\hline & lys7, trpl & 11 & 15 & 25 & & 25 \\
\hline & trpl, ura3 & 23 & 20 & 8 & & 8 \\
\hline & spt 5, ura3 & 19 & 20 & 12 & & 12 \\
\hline
\end{tabular}

${ }^{a}$ PD, parental ditype; NPD, nonparental ditype; TT, tetratype. The spt5-24 allele was scored by its ability to suppress his4-912 $\delta$; $\sec 59$ was scored by its temperature-sensitive lethality at $37^{\circ} \mathrm{C} ; \operatorname{trpl} \Delta I$ and $u r a 3-52$ were scored by their tryptophan and uracil auxotrophies, respectively; lys 7 was scored by mating spore clones to lys7 strains (K396-11A and K396-22B) and scoring diploids for complementation of the lysine auxotrophy. The TRPl allele, which is very tightly linked to CEN4 ( $<1 \mathrm{cM} ; 44)$, and the $U R A 3$ allele, which is tightly linked to $C E N 5(8 \mathrm{cM} ; 44)$, were used to calculate the map distance from SPT5 to CENI3.

${ }^{b}$ Cross 1 was MS113 $\times$ MS192; cross 2 was MS113 $\times$ MS193.

concentration of acidic residues at the amino terminus: residues 1 to 220 had a net charge of -63 . One region of 81 amino acids (residues 137 to 217 ) was $60 \%$ glutamic and aspartic acid and included stretches of 11 and 20 consecutive acidic residues. The amino terminus also included four consensus sites for phosphorylation by casein kinase II (37) at positions $122,188,241$, and 377 . The carboxy terminus of the predicted SPT5 protein (residues 887 to 1063) was $31 \%$ glycine and contained 15 copies of the six-amino-acid sequence S-T/A-W-G-G-A/Q (Table 3).

A computer search of the National Biomedical Research Foundation Protein Sequence data base (version 26; November 1990) did not reveal proteins with significant sequence similarity to SPT5, with the exception of a number of generally acidic or glycine-rich proteins, including nucleolins (38). No other proteins in the data base contained the six-amino-acid repeat S-T/A-W-G-G-A/Q.

The carboxy-terminal repeat region is critical for SPT5 function. Results of our subcloning experiments suggested that the SPT5 carboxy-terminal repeats were required for SPT5 function. A deletion that removed 6 of the 15 repeats (pMS23) impaired complementation of spt5-194 (Fig. 3) and eliminated complementation of the spt 5 null mutation. A deletion that removed all 15 repeats (pMS37) eliminated complementation of both the spt5-194 (Fig. 3) and the spt5 null alleles.

To examine further the importance of the SPT5 peptide repeats, we constructed two SPT5-lacZ fusions: SPT5(1004)lac $Z$ encodes residues 1 to 1004 of SPT5 and includes nine

FIG. 6. Nucleotide sequence of the SPT5 gene and predicted amino acid sequence of its gene product. Nucleotides are numbered on the left; amino acids are numbered on the right. The termination codon is represented by an asterisk. The runs of 11 and 20 consecutive acidic residues and the 15 copies of the six-amino-acid repeat are underlined. The PvuII and the KpnI sites used to construct SPT5-lacZ fusions and the Sall sites used to construct the $s p t 5$ null allele are indicated. 
CTCTTMGGCCACTTGCGGGMUTCCACGTCTCTGCCACAGTTTCTMATMGCATCGACCATMUTCATCTATTACTGTTMATTAT

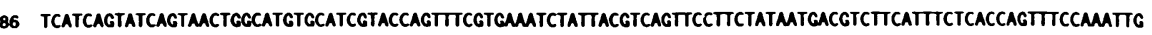

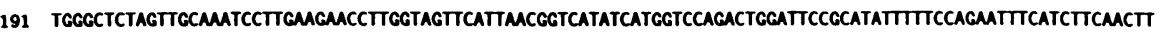

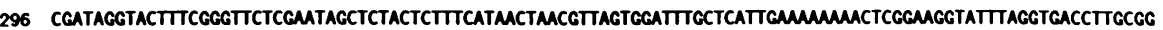

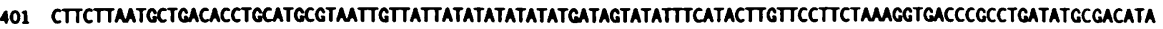

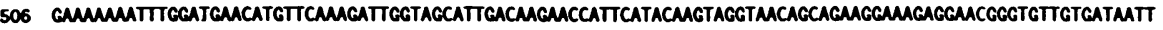

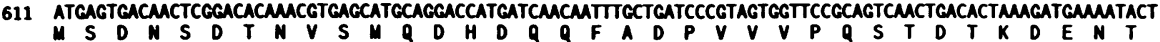

716 AGTGACMUGATACTGTTGATAGTGGCMTGTGACCACMCGCMUGTACAGMCGTCCAGMGTACMGCMTATTCCCCCTTTAGATGGGGMGM MUGM

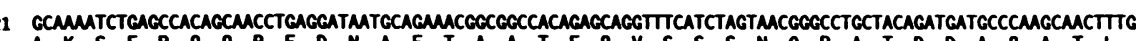
A K S E P Q Q P E D N A E T A A T E Q V S S S N G P A T D D A Q A T L 105

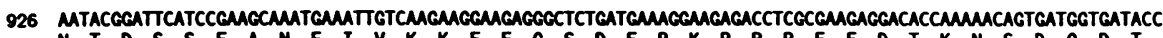
N T D S S E A N E I V K K E E G S D R K R P R E D T K N S D G D T

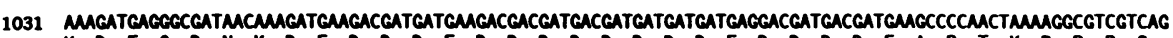

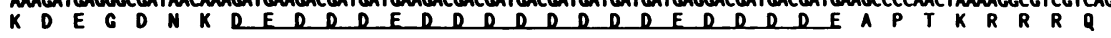

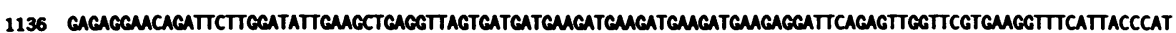
ER N R L D I E A E S S DEDEDEDEED S E L V R E G F I T H

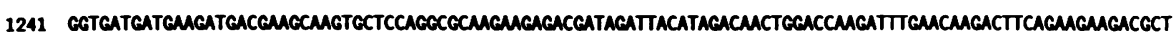
G D D D DEA SA P GARRD DRLHRQLDQDLNKTSE E D

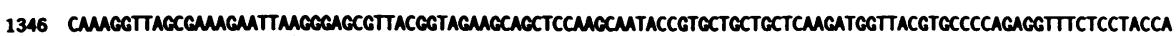
Q R L A K E L R R Y G S S S K Q Y RA A Q D Y Y P Q R F L

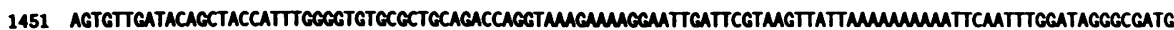
S V D T A T I G V R R P G K E E L I R K L L K K K F N L D R A

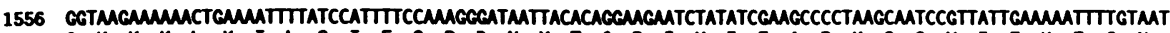
G K K K L K I L S I F Q R D N Y T G R I Y I E A P K Q S V I E K F C N

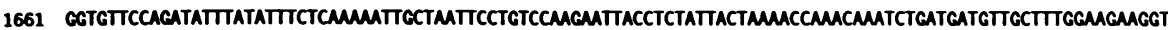
G V P D I Y I S Q K L L I P V Q E L P L L L K P K S D D V A LE E G

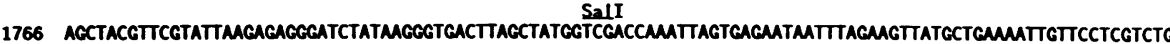
S Y V R I K R G I Y K G D A V D Q I S E N N L E V M L K I V P R L 420

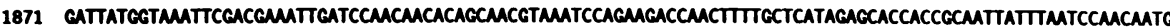
D Y K F D E I D P T T Q R K S R R P T F A R A P P Q L F M P T

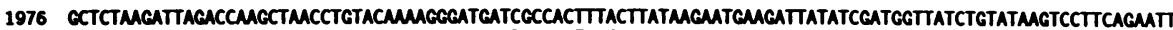
A L R L D Q A N L Y K R D D R H F T Y K N

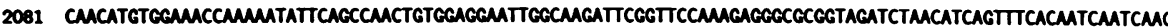
Q H V E T K N I Q P T VEELA R F G S K E G A V D L T S V S Q S I K

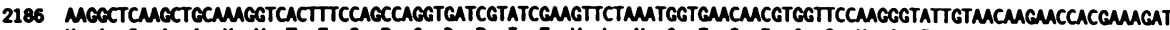
KA Q A A K V T F Q P G DR I E V L NGE QR G S K G I V T R T T K D 560

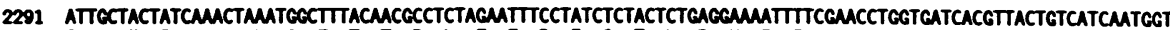
I A T I K L N G F T T P L E F P I S T L R K I F E P G D H V T V I N G 595

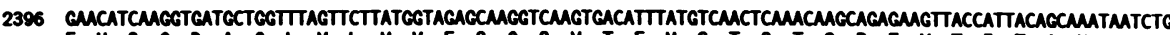
E H Q G D A L V L M V E Q G V T F M S T Q T S R E V T I T A N H L 630

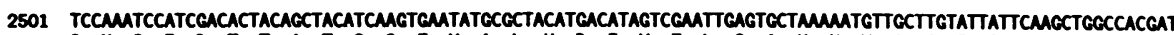
S K S I D T T A T S S E Y A L H D I V E L S A K N V A C I I Q A G H D 665

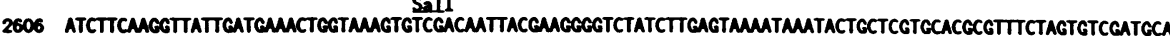
I F K V I D E T G K V S T I T K G S I L S K I N T A R A R V S S V D A 700

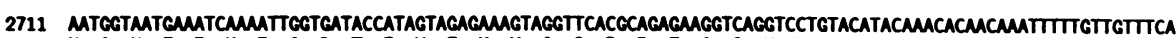
N G N E I K I G D T I VE K V G S R R E G Q V L Y I Q T Q Q I F V V S 735

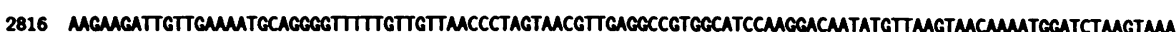
K K I V E N A G V F V V N P S V E A V A S K D N M L S N K M D L S K 770

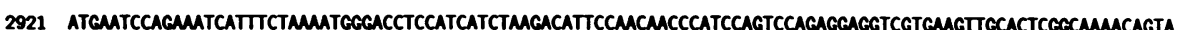
W N P E I I S K M G P P S S K T F Q Q P I Q S R G G R E V A L G K T V 805

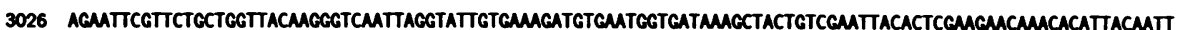
R I R S A G Y K G Q L G I V K D V N G D K A T V E L H S K N K H I T I 840

3131 CACMGCATMGTTMCATATTACMCCGTCAGGGAGGTCMGGTATCACGTATGATGMTTGGTMTAGACGTGGTAGAGTTCCACAGGCCAGMTCGGCCCA D K H K L T Y Y N R E G G E G I Y D E L V NRR G R V P Q A R G P 875

3236 AGTTACGTCAGTGCCCCMAGMACATGGCCACTCGCGGTATTCCAGCAGGTGCTGCGGCTACCTCTTCTGGTCTTAGCGGTGGTATGACACCAGGATGGACCTCC S Y V S A P R N M A T G G I A A G A A A T S S G L S G G M T P G S S 910

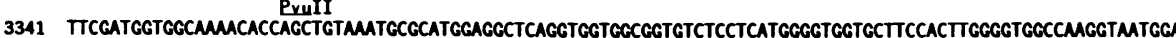
$F$ D G K T P A N A H G G G G G S S G G

3446 GGTGCATCCGCTTGGGGCGGTCCTGGCGGCGGTCCCTCAGCTTGGGGCGGCCMGGTACTGGTCCTACTTCTACTTCGGGTGGTGCTTCAGCCTGGCGTMCMA G A S A G G A G G A S A G G Q G T G A T S I K G G A S A G G N K 980 3551 TCMGTTGGGGCGGTCCATCCACTTGGCCGTCGGGTGGTCMTCTMTGGTCCCATGTCTACTTCGGGTGGTACCGGTGATAGGTCAGCCTACGCCGGGCCTTCC S S G G S S I I A S G G E S N G A M S I G G I G D R S A Y G G A S 1015

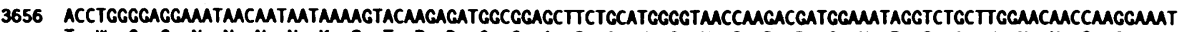
II G G N N N N K S T R D G G A S A G M O D D G N R S A N N N Q G N 1050

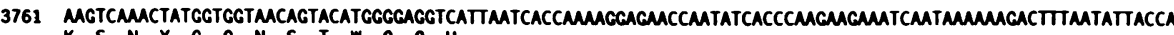
K S N Y G N S I G G H.

3866 CGTTMTAMGMTAGTTATGMGATTTCGATGTTCGATGMATACTGMTCTCGATCCTCGACGATCG 
TABLE 3. SPT5 six-amino-acid repeat ${ }^{a}$

\begin{tabular}{|c|c|c|c|c|c|}
\hline Position & & Seque & ence & & \\
\hline 931 . & $\mathrm{S}$ & $\mathbf{W}$ & G & G & A \\
\hline 937 . & $\mathbf{T}$ & $\mathbf{w}$ & G & G & $Q$ \\
\hline 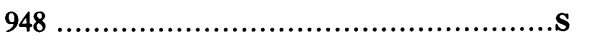 & $\mathbf{A}$ & $\mathbf{W}$ & G & G & A \\
\hline 958 & $\mathbf{A}$ & $\mathbf{W}$ & G & G & Q \\
\hline 969 & $\mathbf{T}$ & $\mathbf{w}$ & G & G & A \\
\hline ................S & $\mathbf{A}$ & $\mathbf{W}$ & G & $\mathrm{N}$ & $\mathrm{K}$ \\
\hline ................s & S & $\mathbf{w}$ & G & G & A \\
\hline 987 . & $\mathbf{T}$ & $\mathbf{w}$ & A & $\mathrm{S}$ & G \\
\hline $1000 \ldots$ & $\mathbf{T}$ & $\mathbf{w}$ & G & G & $\mathrm{T}$ \\
\hline . & $\mathbf{A}$ & $\mathrm{Y}$ & $\mathbf{G}$ & $\mathbf{G}$ & $\mathbf{A}$ \\
\hline 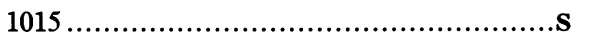 & $\mathbf{T}$ & $\boldsymbol{W}$ & G & G & $\mathrm{N}$ \\
\hline 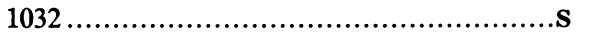 & $\mathbf{A}$ & $\mathbf{W}$ & G & $\mathrm{N}$ & $\mathbf{Q}$ \\
\hline …................................ & $\mathbf{A}$ & $\boldsymbol{W}$ & $\mathrm{N}$ & $\mathrm{N}$ & $\mathbf{Q}$ \\
\hline 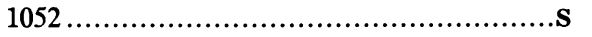 & $\mathrm{N}$ & $\mathrm{Y}$ & $\mathbf{G}$ & $\mathbf{G}$ & $\mathrm{N}$ \\
\hline 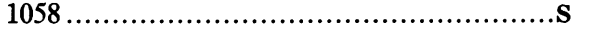 & $\mathbf{T}$ & $\mathbf{W}$ & G & G & $\mathrm{H}$ \\
\hline Consensus... & $\overline{\mathbf{A}}$ & $w$ & G & G & $\bar{Q}$ \\
\hline 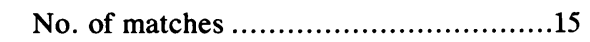 & 12 & 13 & 13 & 11 & 9 \\
\hline
\end{tabular}

a The predicted SPT5 amino acid sequence includes 15 copies of a sixamino-acid repeat at the carboxy terminus. The first serine of each repeat is numbered as in Fig. 6. Residues in boldface type match the consensus, which was derived empirically.

copies of the repeat; SPT5(917)-lacZ encodes residues 1 to 917 of SPT5 and contains no copies of the repeat (Fig. 6). To determine whether either of these SPT5-lacZ fusions complemented the lethal phenotype conferred by an spt5 null mutation, we constructed diploid strains containing each of the SPT5-lacZ fusions integrated at the spt5 $202:: L E U 2$ allele (see Materials and Methods). Tetrad dissection of strains that contained either the SPT5(1004)-lacZ fusion (MS195) or the SPT5(917)-lacZ fusion (MS194) resulted in 4:0 segregation for viability. However, the spore clones that contained the SPT5(917)-lacZ fusion gene were extremely sick, taking 5 to 7 days to form colonies at $23^{\circ} \mathrm{C}$ [as opposed to 2 days for the wild type and 3 days for SPT5(1004)-lacZ strains]. Spore clones that carried either SPT5-lacZ fusion could grow at 30 and $37^{\circ} \mathrm{C}$ and were phenotypically $\mathrm{Spt}^{-}$. Western immunoblot analysis indicated that strains carrying the two fusions (MS194 and MS195) contained approximately the same amount of SPT5- $\beta$-galactosidase protein (63). Therefore, the repeat domain appears to be critical for SPT5 activity.

SPT5 encodes a nuclear protein. To characterize further the SPT5 protein, we used indirect immunofluorescence, as described in Materials and Methods, to determine the cellular location of an SPT5- $\beta$-galactosidase hybrid protein. The results (Fig. 7A to $C$ ) showed that immunofluorescence was coincident with DAPI staining of the nuclear DNA. When treated similarly, an isogenic strain without the fusion was not stained (Fig. 7D to F), demonstrating that the immunofluorescence represented the SPT5- $\beta$-galactosidase hybrid protein. Omission of the anti- $\beta$-galactosidase antibody from the staining procedure also eliminated fluorescein fluorescence. Previous work has demonstrated that $\beta$-galactosidase expressed in yeast cells is located throughout the cytoplasm and nucleus $(25,61)$. Therefore, the observation that an SPT5- $\beta$-galactosidase hybrid protein that contained partial SPT5 function was localized to the nucleus strongly suggests that the wild-type SPT5 protein is located in the nucleus.

\section{DISCUSSION}

Mutations in SPT5 were initially isolated by genetic selections designed to identify genes that are required for normal transcription in $S$. cerevisiae $(19,64)$. Previous genetic results had suggested that the $S P T 5$ gene was related functionally to SPT6. These results include the observations that spt5 and spt6 mutations suppress the same set of mutant alleles, cause double-mutant lethality in haploid cells, and fail to complement in diploid cells $(26,63,64)$. The similarity of the spt5 mutant phenotypes to those of spt6 and also htal-htbl (histone) mutants $(4,12,13,19,26,45,46,62)$ led us to analyze the SPT5 gene and its product as a step toward understanding the roles of these genes in transcription.

Our current work extends the genetic similarities between the SPT5 and SPT6 genes and has also revealed interesting features common to the SPT5 and SPT6 gene products. First, spt5 and spt6 mutations cause similar alterations in transcription of the his4-912 $\delta$ and lys2-128 alleles (Fig. 1 and $2 ; 13)$. Second, spt5 and spt6 null mutations each cause lethality $(13,45)$. Third, increased or decreased gene dosage of either SPT5 or SPT6 confers similar mutant phenotypes (Fig. 4 ; 13). Finally, as judged from immunofluorescence microscopy of fusion proteins, both SPT5 and SPT6 appear to be nuclear proteins (Fig. 7; 61).

The nucleotide sequence of the SPT5 gene also revealed similarities to the SPT6 gene. Both predicted proteins have a high concentration of acidic residues at the amino terminus. The sequence of SPT5 predicted a region of 81 amino acids that was $60 \%$ glutamic acid and aspartic acid. Likewise, the SPT6 nucleotide sequence revealed that $50 \%$ of the first 70 amino acids were glutamic acid and aspartic acid (61). The acidic domains of both proteins contain a number of potential sites for phosphorylation by casein kinase II (37).

One class of proteins that have extremely acidic domains are proteins thought to interact with chromatin (see reference 15 for a review). One of these proteins, nucleolin, has both an acidic amino terminus and a glycine-rich carboxy terminus (38), similar to SPT5. Several transcription factors, including the yeast proteins GAL4 (39) and GCN4 $(30,31)$, have acidic domains that are required for activation of transcription; however, these acidic domains are generally less extensive and less acidic than those predicted for the SPT5 and SPT6 proteins. The human nucleolar transcription factor hUBF does contain a highly acidic carboxy-terminal region (33).

The carboxy-terminal 132 amino acids of the predicted SPT5 protein include 15 copies of the six-amino-acid repeat S-T/A-W-G-G-A/Q. Deletion of the SPT5 sequences encoding six of the 15 repeats impaired SPT5 function, while deletion of all 15 repeats virtually eliminated SPT5 function, as judged by complementation of $s p t 5$ mutations. Analysis of two SPT5-lacZ fusion genes that encoded either zero or nine copies of the six-amino-acid repeat also indicated that the repeat domain was critical for SPT5 function. In our analysis of the requirement for the repeat domain, fusions to $\beta$-galactosidase appeared to increase slightly the activity of SPT5, possibly by stabilizing the SPT5 portion of the hybrid protein. However, this result does not necessarily mean that the function of the repeats is to stabilize the SPT5 protein. Other possible roles for the SPT5 repeats are to promote protein-protein interactions or to regulate SPT5 activity.

Although no other gene sequences in a large data base predicted proteins with significantly similar repeat sequences, the SPT5 repeat is somewhat reminiscent of the heptapeptide carboxy-terminal repeat of the largest subunit 

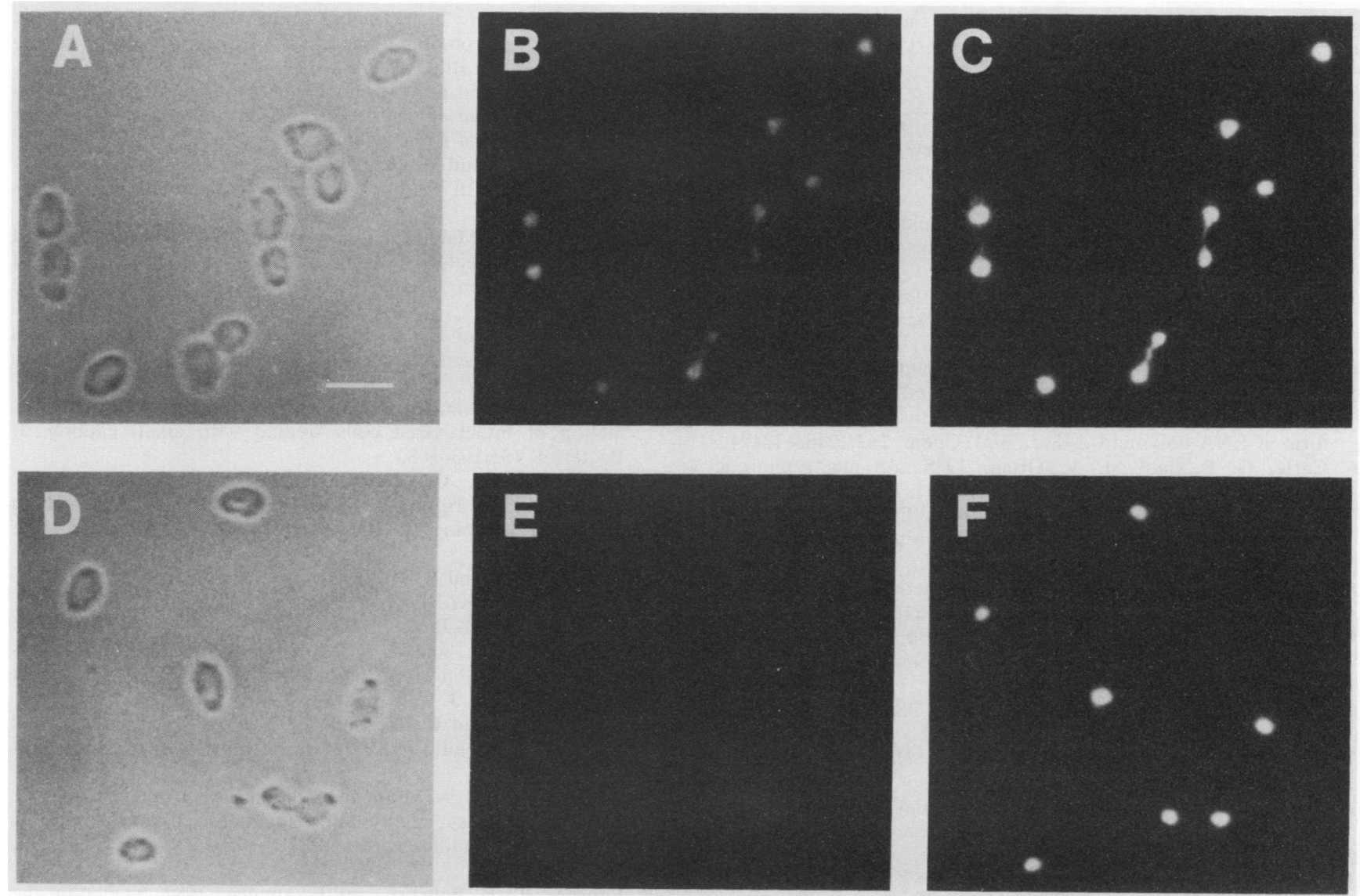

FIG. 7. Nuclear localization of SPT5- $\beta$-galactosidase. Strain BM467, containing the SPT5(1004)- $\beta$-galactosidase hybrid protein (A to C), and strain BM339, a control strain lacking the hybrid protein (D to F), were stained with anti- $\beta$-galactosidase antibody and a fluorescein-conjugated secondary antibody as described in Materials and Methods. Micrographs show phase-contrast (A and D), fluorescein fluorescence (B and E), and DAPI fluorescence, which stains the DNA (C and F). Bar $=10 \mu \mathrm{m}$.

of RNA polymerase II (consensus = P-T-S-P-S-Y-S). Both the SPT5 and the RNA polymerase repeats contain residues that could be phosphorylated $(S, T)$, residues known to disrupt secondary structure of proteins $(G, P)$, and an aromatic residue (W, Y). The RNA polymerase repeat is present in eukaryotic RNA polymerases in 26 (yeast) to 52 (mouse) copies (see reference 14 for a review), is phosphorylated (5; reviewed in reference 55), and is required in vivo for yeast RNA polymerase function (47), but its function is not yet known.

One model consistent with our gene dosage results is that the SPT5 and SPT6 proteins function as part of a complex that is sensitive to the stoichiometry of its components. However, strains that contain both SPT5 and SPT6 on high-copy-number plasmids also have an $\mathrm{Spt}^{-}$phenotype (data not shown), suggesting that these are not the only components of the putative complex. Genetic analysis indicates that at least one more gene product, the SPT4 protein, may be required for the function of this putative complex. Mutations in SPT4 cause phenotypes similar to those of spt5 and spt6 mutations, cause double-mutant lethality with spt5 and spt6 mutations, and fail to complement spt 5 and spt6 mutations $(63,64)$. SPT4, however, is distinct in several respects: the gene is not essential for growth, altered dosage does not cause a mutant phenotype, and the SPT4 protein is not acidic (40).
Previous genetic analyses of spt mutants revealed a number of similarities between spt5, spt6, and histone (htall sptll and htb1/sptl2) mutant strains. Mutations in these genes suppress the same spectrum of Ty and $\delta$ insertion mutations as well as some cis- and trans-acting mutations that greatly reduce expression of the $S U C 2$ gene and Ty elements $(4,12,13,19,26,45,46,62)$. Furthermore, histone gene pairs, like SPT5 and SPT6, exhibit interesting dosage effects: an increase or a decrease in the gene copy number causes an $\mathrm{Spt}^{-}$phenotype (12). We have now found that SPT5 and SPT6 encode essential nuclear proteins with highly acidic amino termini. Given these mutant phenotypes and physical characteristics, we favor a model in which the SPT5 and SPT6 proteins act together to affect chromatin structure, thereby influencing gene expression in yeast cells. Examination of chromatin structure in these spt mutants should begin to address this model directly.

\section{ACKNOWLEDGMENTS}

We are grateful to Joel Hirschhorn and David Eisenmann for helpful comments on the manuscript and to David Eisenmann for bringing to our attention the similarity of the SPT5 and RNA polymerase repeat domains.

This work was supported by National Institutes of Health grant GM32967, National Science Foundation grant DCB8451649, and a grant from the Stroh Brewing Company to F.W. M.S.S. and E.M. 
were supported by an NIH training grant to the Genetics Program (T32-GM07196) and by the Lucille P. Markey Charitable Trust.

\section{REFERENCES}

1. Andreadis, A., Y.-P. Hsu, G. B. Kohlhaw, and P. Schimmel. 1982. Nucleotide sequence of yeast $L E U 2$ shows 5 '-noncoding region has sequences cognate to leucine. Cell 31:319-325.

2. Birnboim, H. C., and J. Doly. 1979. A rapid alkaline extraction procedure for screening recombinant plasmid DNA. Nucleic Acids Res. 7:1513-1523.

3. Boyer, H. W., and D. Roulland-Dussoix. 1969. A complementation analysis of the restriction and modification of DNA in $E$. coli. J. Mol. Biol. 41:458-472.

4. Brown, S. A., and F. Winston. Unpublished data.

5. Cadena, D. L., and M. E. Dahmus. 1987. Messenger RNA synthesis in mammalian cells is catalyzed by the phosphorylated form of RNA polymerase II. J. Biol. Chem. 262:12468-12474.

6. Carle, G. F., and M. V. Olson. 1985. An electrophoretic karyotype for yeast. Proc. Natl. Acad. Sci. USA 82:3756-3760.

7. Carlson, M., and D. Botstein. 1982. Two differentially regulated mRNAs with different 5 ' ends encode secreted and intracellular forms of yeast invertase. Cell 28:145-154.

8. Chaleff, D. T., and G. R. Fink. 1980. Genetic events associated with an insertion mutation in yeast. Cell 21:227-237.

9. Chu, G., D. Vollrath, and R. W. Davis. 1986. Separation of large DNA molecules by contour-clamped homogeneous electric fields. Science 234:1582-1585.

10. Church, G. M., and W. Gilbert. 1984. Genomic sequencing. Proc. Natl. Acad. Sci. USA 81:1991-1995.

11. Clark-Adams, C. D. 1988. Ph.D. thesis. Harvard University, Cambridge, Mass.

12. Clark-Adams, C. D., D. Norris, M. A. Osley, J. S. Fassler, and F. Winston. 1988. Changes in histone gene dosage alter transcription in yeast. Genes Dev. 2:150-159.

13. Clark-Adams, C. D., and F. Winston. 1987. The SPT6 gene is essential for growth and is required for $\delta$-mediated transcription in Saccharomyces cerevisiae. Mol. Cell. Biol. 7:679-686.

14. Cornelissen, A. W. C. A., R. Evers, and J. Kock. 1988. Structure and sequence of genes encoding subunits of eukaryotic RNA polymerases. Oxford Surv. Eukaryotic Genes 5:91-131.

15. Earnshaw, W. C. 1987. Anionic regions in nuclear proteins. J. Cell Biol. 105:1479-1482.

16. Eisenmann, D. M., C. Dollard, and F. Winston. 1989. SPT15, the gene encoding the yeast TATA binding factor TFIID, is required for normal transcription initiation in vivo. Cell 58:11831191.

17. Eisenmann, D. M., and F. Winston. Unpublished data.

18. Farabaugh, P. J., and G. R. Fink. 1980. Insertion of the eukaryotic transposable element $\mathrm{Ty} 1$ creates a 5-base pair duplication. Nature (London) 286:352-356.

19. Fassler, J. S., and F. Winston. 1988. Isolation and analysis of a novel class of suppressor of Ty insertion mutations in Saccharomyces cerevisiae. Genetics 118:203-212.

20. Fassler, J. S., and F. Winston. 1989. The Saccharomyces cerevisiae SPT13/GAL11 gene has both positive and negative regulatory roles in transcription. Mol. Cell. Biol. 9:5602-5609.

21. Feinberg, A. P., and B. Vogelstein. 1983. A technique for radiolabeling restriction endonuclease fragments to high specific activity. Anal. Biochem. 132:6-13.

22. Feinberg, A. P., and B. Vogelstein. 1984. A technique for radiolabeling restriction endonuclease fragments to high specific activity. Addendum. Anal. Biochem. 137:266-267.

23. Floy, K., and P. Heiter (Johns Hopkins University Medical School). Personal communication.

24. Gerring, S. L., C. Connelly, and P. Heiter. 1990. Positional mapping of genes by chromosome blotting and chromosome fragmentation. Methods Enzymol. 194:57-77.

25. Hall, M. N., L. Hereford, and I. Herskowitz. 1984. Targeting of $E$. coli $\beta$-galactosidase to the nucleus in yeast. Cell 36:10571065.

26. Happel, A. M., M. S. Swanson, and F. Winston. Genetics, in press.
27. Hirschman, J. E., K. J. Durbin, and F. Winston. 1988. Genetic evidence for promoter competition in Saccharomyces cerevisiae. Mol. Cell. Biol. 8:4608-4615.

28. Hoffman, C., and F. Winston. 1987. A ten-minute DNA preparation from yeast efficiently releases autonomous plasmids for transformation of Escherichia coli. Gene 57:267-272.

29. Holmes, D. S., and M. Quigley. 1981. A rapid boiling method for the preparation of bacterial plasmids. Anal. Biochem. 114:193197.

30. Hope, I. A., S. Mahadevan, and K. Struhl. 1988. Structural and functional characterization of the short acidic transcriptional activation region of yeast GCN4 protein. Nature (London) 333:635-640.

31. Hope, I. A., and K. Struhl. 1986. Functional dissection of a eukaryotic transcriptional activator protein, GCN4 of yeast. Cell 46:885-894.

32. Ito, H., Y. Fukuda, K. Marata, and A. Kimura. 1983. Transformation of intact yeast cells treated with alkali cations. J. Bacteriol. 153:163-168.

33. Jantzen, H.-M., A. Admon, S. P. Bell, and R. Tjian. 1990 Nucleolar transcription factor hUBF contains a DNA binding motif with homology to HMG proteins. Nature (London) 344: 830-836.

34. Johnston, M., and R. W. Davis. 1984. Sequences that regulate the divergent GALI-GAL10 promoter in Saccharaomyces cerevisiae. Mol. Cell. Biol. 4:1440-1448.

35. Kilmartin, J. V., and A. E. M. Adams. 1984. Structural rearrangements of tubulin and actin during the cell cycle of the yeast Saccharomyces. J. Cell Biol. 98:922-933.

36. Klapholz, S., and R. Esposito. 1982. A new mapping method employing a meiotic $\mathrm{rec}^{-}$mutant of yeast. Genetics 100:387412.

37. Kuenzel, E. A., J. A. Mulligan, J. Sommercorn, and E. G. Krebs. 1987. Substrate specificity determinants for casein kinase II as deduced from studies with synthetic peptides. J. Biol. Chem 262:9136-9140.

38. Lapeyre, B., H. Bourbon, and F. Amalric. 1987. Nucleolin, the major nucleolar protein of growing eukaryotic cells: an unusual protein structure revealed by nucleotide sequence. Proc. Natl. Acad. Sci. USA 84:1472-1476.

39. Ma, J., and M. Ptashne. 1987. Deletion analysis of GALA defines two transcriptional activating segments. Cell 48:847-853.

40. Malone, E. A., J. S. Fassler, and F. Winston. Unpublished data.

41. Maniatis, T., E. F. Fritsch, and J. Sambrook. 1982. Molecular cloning: a laboratory manual. Cold Spring Harbor Laboratory, Cold Spring Harbor, N.Y.

42. Meyers, A. M., A. Tzagoloff, D. M. Kinney, and C. J. Lusty. 1986. Yeast shuttle and integrative vectors with multiple cloning sites suitable for construction of lac Z fusions. Gene 45:299-310.

43. Mortimer, R. K., and D. C. Hawthorne. 1969. Yeast genetics, p. 385-460. In A. H. Rose and J. S. Harrison (ed.), The yeasts, vol. 1. Academic Press, Inc., New York.

44. Mortimer, R. K., and D. Schild. 1980. Genetic map of Saccharomyces cerevisiae. Microbiol. Rev. 44:519-571.

45. Neigeborn, L., J. L. Celenza, and M. Carlson. 1987. SSN20 is an essential gene with mutant alleles that suppress defects in SUC2 transcription in Saccharomyces cerevisiae. Mol. Cell. Biol. 7:672-678

46. Neigeborn, L., K. Rubin, and M. Carlson. 1986. Suppressors of snf2 mutations restore invertase derepression and cause temperature-sensitive lethality in yeast. Genetics 112:741-753.

47. Nonet, M., D. Sweetser, and R. Young. 1987. Functional redundancy and structural polymorphism in the largest subunit of RNA polymerase II. Cell 50:909-915.

48. Norrander, J., T. Kempe, and J. Messing. 1983. Construction of improved M13 vectors using oligodeoxynucleotide-directed mutagenesis. Gene 26:101-106.

49. Peck, L. (Harvard University). 1983. Personal communication.

50. Rigby, P. W., M. Diekman, C. Rhodes, and P. Berg. 1977. Labeling deoxyribonucleic acid to high specific activity in vitro by nick translation with DNA polymerase I. J. Mol. Biol. 113:237-251.

51. Roeder, G. S., and G. R. Fink. 1980. DNA rearrangements 
associated with a transposable element in yeast. Cell 21:239249.

52. Rose, M. D., P. Novick, J. H. Thomas, D. Botstein, and G. R. Fink. 1987. A Saccharomyces cerevisiae genomic plasmid bank based on a centromere-containing shuttle vector. Gene 60:237243.

53. Rothstein, R. 1983. One step gene disruption in yeast. Methods Enzymol. 101:202-211.

54. Sanger, F., S. Nicklen, and A. R. Coulson. 1977. DNA sequencing with chain-terminating inhibitors. Proc. Natl. Acad. Sci. USA 74:5463-5467.

55. Sentenac, A. 1985. Eukaryotic RNA polymerases. Crit. Rev. Biochem. 18:31-90.

56. Sherman, F., G. R. Fink, and C. W. Lawrence. 1978. Methods in yeast genetics: a laboratory manual, revised ed. Cold Spring Harbor Laboratory, Cold Spring Harbor, N.Y.

57. Sikorski, R. S., and P. Heiter. 1989. A system of shuttle vectors and yeast host strains designed for efficient manipulation of DNA in Saccharomyces cerevisiae. Genetics 122:19-27.

58. Silverman, S. J., and G. R. Fink. 1984. Effects of Ty insertions on HIS4 transcription in Saccharomyces cerevisiae. Mol. Cell. Biol. 4:1246-1251.

59. Simchen, G., F. Winston, C. A. Styles, and G. R. Fink. 1984. Ty-mediated expression of the LYS2 and HIS4 genes of Sac- charomyces cerevisiae is controlled by the same SPT genes. Proc. Natl. Acad. Sci. USA 81:2431-2434.

60. Som, T., K. A. Armstrong, F. C. Volkert, and J. R. Broach. 1988. Autoregulation of $2 \mu$ circle gene expression provides a model for maintenance of stable plasmid copy levels. Cell 52:27-37.

61. Swanson, M. S., M. Carlson, and F. Winston. 1990. SPT6, an essential gene that affects transcription in Saccharomyces cerevisiae, encodes a nuclear protein with an extremely acidic amino terminus. Mol. Cell. Biol. 10:4935-4941.

62. Swanson, M. S., J. N. Hirschhorn, S. A. Brown, and F. Winston. Unpublished data.

63. Swanson, M. S., and F. Winston. Unpublished data.

64. Winston, F., D. T. Chaleff, B. Valent, and G. R. Fink. 1984. Mutations affecting Ty-mediated expression of the HIS4 gene of Saccharomyces cerevisiae. Genetics 107:179-197.

65. Winston, F., C. Dollard, E. A. Malone, J. Clare, J. G. Kapakos, P. Farabaugh, and P. Minehart. 1987. Three genes are required for trans-activation of Ty transcription in yeast. Genetics 115: 649-656.

66. Winston, F., K. J. Durbin, and G. R. Fink. 1984. The SPT3 gene is required for normal transcription of Ty elements in $S$. cerevisiae. Cell 39:675-682. 